\title{
Visceral and skin granuloma annulare, diabetes, and polyendocrine disease
}

\author{
D J B THOMAS, M RADEMAKER, D D MUNRO, D A LEVISON, G M BESSER
}

\section{Abstract}

A middle aged man suffered with insulin dependent diabetes, autoimmune Addison's disease, myxoedema, and severe ulcerative colitis, for which he had undergone subtotal colectomy with formation of an ileostomy. Granuloma annulare confined to the anterior abdominal wall was diagnosed in 1981 . In 1983 an episode of severe colicky pain and excessive working of the ileostomy occurred associated with severe hyperglycaemia and increased irritation of the granuloma annulare. Laparotomy disclosed adhesions and numerous white nodules over bowel, mesentery, and peritoneum histologically identical with the skin lesions. Two further episodes of subacute small bowel obstruction occurred, and a repeat laparotomy showed widespread intraabdominal granuloma annulare.

Visceral granuloma annulare appears not to have been reported before, and in this patient exacerbation of the skin lesion was associated with poor diabetic control.

\section{Introduction}

Granuloma annulare was first described by Fox in $1895 .^{1}$ It is a rare disease which is usually localised to the extremities but which may become generalised. The aetiology is unknown but the disease has been linked to trauma, insect bites, sarcoidosis, and diabetes. ${ }^{2}$
Departments of Endocrinology, Dermatology, and Histopathology, St Bartholomew's Hospital, London EC1A 7BE

D J B THOMAS, MD, MRCP, senior registrar in endocrinology

$M$ RADEMAKER, BM, MRCP, registrar in dermatology

D D MUNRO, MD, FRCP, consultant dermatologist

D A LEVISON, MB, MRCPATH, senior lecturer in histopathology

G M BESSER, DSC, FRCP, professor of endocrinology

\section{Case report}

A man aged 50 had developed insulin dependent diabetes at the age of 24 , autoimmune Addison's disease at the age of 41 , and myxoedema when aged 42. He was positive for thyroid microsomal antibodies (1/40) and adrenal antibodies. His father had myxoedema and a brother had insulin dependent diabetes. In 1981 he re-presented with both vitiligo and a raised purplish rash confined to his anterior abdominal wall. The lesion was thought to be granuloma annulare and subsequent skin biopsy confirmed this (see below). The patient also had severe ulcerative colitis, which had started in the early 1960 s and later required a subtotal colectomy with ileostomy.

In April 1983 the patient was admitted with colicky abdominal pain and excessive working of the ileostomy. His diabetes was out of control with severe hyperglycaemia. He complained that his granuloma annulare was irritating, and it appeared more florid. There was a closed loop obstruction of the proximal jejunum, and exploratory laparotomy showed multiple adhesions and numerous white nodules studded over the bowel, mesentery, and peritoneum. Histologically these were identical with the skin lesions and were considered to be part of the granuloma annulare. The patient presented twice more with subacute bowel obstruction, and a further laparotomy showed widespread intra-abdominal granuloma annulare.

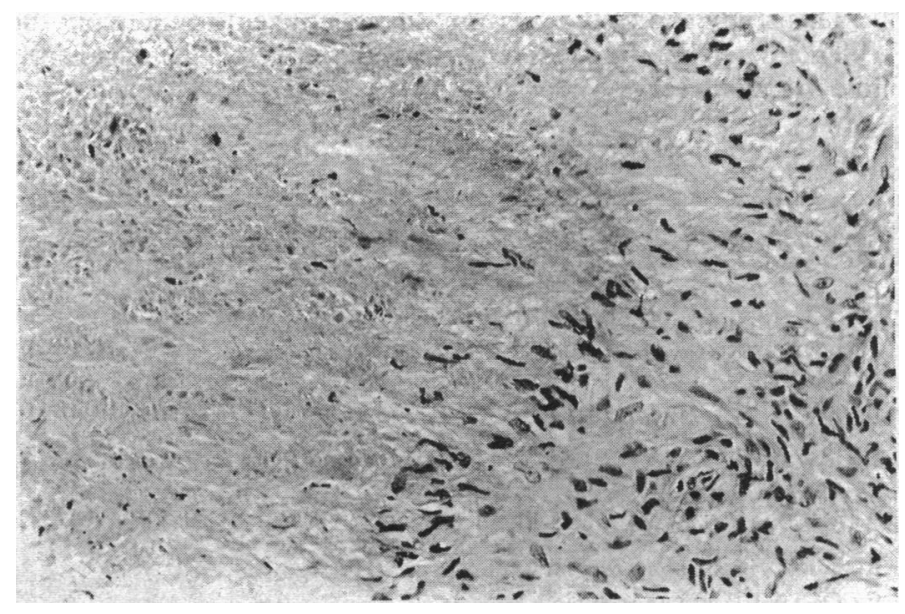

Histological section of edge of granuloma in mesentery. 


\section{Discussion}

We failed to find a record of intra-abdominal granuloma annulare lesions, and this case appears to be the first of visceral granuloma annulare. The relation between diabetes mellitus and generalised granuloma annulare has been a subject of speculation for years but remains unclear. Haim et al reported 13 patients with generalised granuloma annulare, three of whom had overt mild non-insulin dependent diabetes and seven others carbohydrate intolerance after provocative oral prednisolone. ${ }^{3}$ Other studies, however, have not confirmed this observation. A more recent report has suggested an association between granuloma annulare and insulin dependent diabetes. ${ }^{4}$ The relation between diabetes and granuloma annulare is made more complex by the histological appearance of necrobiosis lipoidica diabeticorum, granuloma annulare, and rheumatoid nodules. Each of these conditions includes collagen necrobiosis, and all three variants have been seen in a patient who had insulin dependent diabetes and a sister with rheumatoid arthritis. ${ }^{5}$ The histological similarities among these conditions are so great that they may share the same or a very similar pathogenesis. Immune complex deposition seems the most probable common pathway.

Finally, in our patient there appeared to be a relation between diabetic control and the granuloma annulare. Poor diabetic control $\underline{T}$ was associated with an exacerbation of the lesion, which in turn 3 resulted in excessive working of the ileostomy, which was evident whatever the cause of his poor diabetic control.

Biopsy sections of the skin and mesenteric nodes showed severalo discrete foci of connective tissue necrosis in the dermis and subcutaneous fat. The zones of necrosis were surrounded by histiocytes showing well marked palisading (figure). The histiocyteक reaction was not strikingly tuberculoid. There were no giant cells, and no evidence of arteritis was detected.

\section{References}

1 Fox TC. Ringed eruption of the fingers. Br 7 Dermatol 1895;7:91-5.

2 Muhlbaver JE. Granuloma annulare. $f$ Am Acad Dermatol 1980;3:217-30.

Haim S, Fiedman-Birnbaum R, Shafrir A. Generased gran:30ma angulare: relion diabetes mellitus as revealed in 8 cases. Br f Dermatol 1970;83:302-5.

4 Muhlemann MF, Williams DR. Granuloma annulare and diabetes mellitus-an association. $B r f \vec{O}$ Dermatol $1984 ; 26$ (suppl):12-3.

5 Burton JL. Granuloma annulare, rheumatoid nodules and necrobiosis lipoidica. Br $\mathcal{f}$ Dermatol $\vec{\omega}$ 1977;97:52-4.

(Accepted 22 August 1986)

\title{
Impaired cell mediated immunity in haemophilia in the absence of infection with human immunodeficiency virus
}

\author{
RAJAN MADHOK, \\ A GRACIE \\ G D O LOWE, \\ A BURNETT, \\ K FROEBEL, \\ E FOLLETT, \\ C D FORBES
}

\begin{abstract}
The cell mediated immune response was evaluated in vivo in 29 patients with clinically severe haemophilia by means of the dinitrochlorobenzene skin test. All patients had a response below the median normal value, and in 19 the response was on or below the lower limit of the normal range. There was no difference in skin response between patients positive and negative for the human immunodeficiency virus (HIV; formerly known as human $T$ cell lymphotropic virus III or lymphadenopathy associated virus). In the whole group, and in seronegative patients $(n=17)$, there was aan inverse relation between exposure to clotting factor and skin response. In seropositive patients $(n=12)$ no such association was apparent.
\end{abstract}

This study shows that clotting factor concentrate impairs the cell mediated immune response to a new antigen in the absence of infection with HIV.

\footnotetext{
University Department of Medicine, Glasgow Royal Infirmary, Glasgow G31 2ER

RAJAN MADHOK, MB, MRCP, registrar

A GRACIE, BSC, research assistant

G D O LOWE, MD, MRCP, senior lecture

K FROEBEL, PHD, research fellow

C D FORBES, MD, FRCP, reader

Leukaemia Research Fund Laboratory, Department of Haematology, Glasgow Royal Infirmary

A BURNETT, MRCPATH, consultant

Regional Virus Laboratory, Ruchill Hospital, Glasgow

E FOLLETT, PHD, consultant

Correspondence to: Dr Madhok.
}

\section{Introduction}

The acquired immune deficiency syndrome (AIDS) seems to be $\frac{\circ}{\Phi}$ caused by a retrovirus, the human immunodeficiency virus (HIV) (formerly known as human $\mathrm{T}$ lymphotropic virus type III or $\frac{0}{3}$ lymphadenopathy associated virus). ${ }^{12}$ Little is known of the clinical course of infection with HIV, but a range of disease is seen.$^{3}$ It is not known what factors determine progression from the asymptomatic carrier stage to AIDS. Epidemiological data suggest that both the initial infection and its progression to AIDS require additional predisposing or cooperative factors, ${ }^{4-6}$ and both infectious and noninfectious cofactors have been suggested. ${ }^{78}$

Haemophiliacs who have received treatment with lyophilised $\delta$ clotting factor concentrate are at increased risk of AIDS. Inverted $₹$ ratios of $T$ helper to $T$ suppressor lymphocytes have been reported $\frac{}{2}$ in haemophiliacs in the absence of infection with HIV, ${ }^{90}$ and it has $N$ been suggested that HIV is itself an opportunistic pathogen in an already immunocompromised host. ${ }^{911}$ We previously showed that lyophilised factor VIII concentrate in vitro has immunosuppressive properties in tissue cultures of human leucocytes. ${ }^{12}$

The aim of this study was to determine whether haemophiliacs $\omega$ treated with factor concentrates show immunosuppression. The dinitrochlorobenzene skin test is considered to be the best single test to evaluate the cell mediated immune response in vivo ${ }^{1314} \Phi$ and measures a person's ability to respond to a new antigen, $\stackrel{+}{-}$ as dinitrochlorobenzene is rarely encountered. The score on dinitrochlorobenzene testing was compared with exposure to clotting factor and HIV antibody state.

\section{Patients and methods}

We studied 29 patients with clinically severe haemophilia (factor VIII or IX concentration <50U/1) attending the Glasgow adult haemophilia centre, $\stackrel{\supset}{\supset}$ 